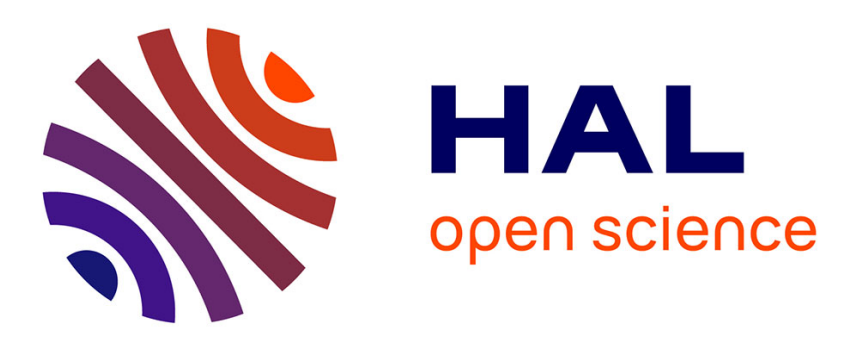

\title{
Influence of temperature in a mass transfer simulation: application to wood
}

Maximin Varnier, Nicolas Sauvat, Laurent Ulmet, Cédric Montero, Frédéric

Dubois, Joseph Gril

\section{- To cite this version:}

Maximin Varnier, Nicolas Sauvat, Laurent Ulmet, Cédric Montero, Frédéric Dubois, et al.. Influence of temperature in a mass transfer simulation: application to wood. Wood Science and Technology, 2020, 54 (4), pp.943-962. 10.1007/s00226-020-01197-y · hal-02996011

\section{HAL Id: hal-02996011 \\ https://hal.science/hal-02996011}

Submitted on 9 Nov 2020

HAL is a multi-disciplinary open access archive for the deposit and dissemination of scientific research documents, whether they are published or not. The documents may come from teaching and research institutions in France or abroad, or from public or private research centers.
L'archive ouverte pluridisciplinaire HAL, est destinée au dépôt et à la diffusion de documents scientifiques de niveau recherche, publiés ou non, émanant des établissements d'enseignement et de recherche français ou étrangers, des laboratoires publics ou privés. 


\title{
Influence of temperature in a mass transfer simulation: Application to wood
}

\author{
Maximin Varnier ${ }^{1}$, Nicolas Sauvat ${ }^{1}$, Laurent Ulmet ${ }^{1}$, Cédric Montero ${ }^{2}$, Frédéric Dubois ${ }^{1}$, \\ Joseph Gril ${ }^{3}$ \\ ${ }^{1}$ Univ. Limoges, GC2D, EA 3178, France \\ ${ }^{2}$ Univ. Montpellier, CNRS, LMGC, Montpellier, France \\ ${ }^{3}$ Univ. Clermont-Auvergne, CNRS, Sigma Clermont, Institut Pascal, Clermont-Ferrand, \\ France
}

Scientific contact: Nicolas Sauvat ${ }^{1}$, ORCID ID 0000-0002-3381-4276

\begin{abstract}
For in situ timber structures applications, heat and mass transfer are strongly dependent on temperature. This work focuses on a parametrical modeling to evaluate and quantify temperature effect at each stage. The model is classically based on a coupling between Fourier's Law, which establishes the temporal and spatial distribution of temperature, and Fick's Law dealing specifically with the water field distribution. Several hypotheses are proposed and discussed in this work as regards thermal coupling. In particular, it is shown how to integrate temperature into a permeability correction. Also proposed herein is an interaction between temperature and the sorption isotherm. The model incorporates partial adsorption and desorption isotherms. Implementation in a finite element software allows highlighting the various couplings, in comparison with more standard calculus approaches.
\end{abstract}

Keywords: Heat and mass transfer, timber elements, temperature and moisture content coupling, analytical model.

\section{Acknowledgements}

This work has been realised in the French National Research Agency (ANR) through EFEUR5 project (ANR-15-CE08-0027) concerning Structural behavior of French Hardwood for better optimization with Eurocodes 5. The authors would like to express their appreciation towards the ANR financial support.

\section{List of symbols}

\section{$\underline{\text { Latin symbols }}$}

A, B , $\beta$ : Fitting parameters of water capacity, dimensionless

$\mathrm{A}_{\mathrm{a}}: \quad$ Fitting parameter of $\Delta \mathrm{H}_{\mathrm{s}}$ in adsorption, in $\mathrm{J} \mathrm{kg}^{-1}$

$\mathrm{A}_{\mathrm{d}}$ : $\quad$ Fitting parameter of $\Delta \mathrm{H}_{\mathrm{s}}$ in desorption, in $\mathrm{J}_{\mathrm{kg}} \mathrm{kg}^{-1}$

\footnotetext{
1 nicolas.sauvat@unilim.fr
} 
$\mathrm{C}_{\mathrm{W}}: \quad$ Heat capacity of water, in $\mathrm{J} \cdot \mathrm{kg}^{-1} \cdot \mathrm{K}^{-1}$

$\mathrm{C}_{\mathrm{h}}$ : $\quad$ Homogenized heat capacity, in $\mathrm{J}_{\mathrm{kg}} \mathrm{kg}^{-1} \cdot \mathrm{K}^{-1}$

$\mathrm{C}_{\mathrm{anh}}$ : $\quad$ Dry heat capacity, in $\mathrm{J} \cdot \mathrm{kg}^{-1} \cdot \mathrm{K}^{-1}$

$\mathrm{C}_{\mathrm{pv}}: \quad$ Heat capacity of vapor, in $\mathrm{J} \cdot \mathrm{kg}^{-1} \cdot \mathrm{K}^{-1}$

$\mathrm{D}_{\mathrm{T}}: \quad$ Heat transfer tensor, in $\mathrm{m}^{2} \cdot \mathrm{s}^{-1}$

$\mathrm{D}_{\mathrm{W}}: \quad \quad$ Moisture transfer tensor, in $\mathrm{m}^{2} \cdot \mathrm{s}^{-1}$

$\mathrm{D}_{\mathrm{wT}}$ : $\quad$ Hygrothermal coupling tensor (Soret's effect), in $\mathrm{m}^{2} \cdot \mathrm{s}^{-1}$

$\mathrm{D}_{\mathrm{Tw}}: \quad$ Thermo-hydric coupling tensor, in $\mathrm{m}^{2} \cdot \mathrm{s}^{-1}$

$\mathrm{E}_{\mathrm{a}}: \quad$ Activation energy, in ${\mathrm{J} . \mathrm{kg}^{-1}}^{-1}$

$\mathrm{h}_{\mathrm{T}}: \quad$ Convective heat transfer coefficient, in $\mathrm{W} \cdot \mathrm{m}^{-2} \cdot \mathrm{K}^{-1}$

$\mathrm{h}_{\mathrm{w}}$ : $\quad$ Convective moisture transfer coefficient, in s.m $\mathrm{m}^{-1}$

$\mathrm{H}_{\mathrm{s}}$ : $\quad$ Sorption latent heat, in $\mathrm{kJ} \cdot \mathrm{kg}^{-1}$

$\Delta \mathrm{H}_{\mathrm{s}}$ : $\quad$ Latent heat of sorption of bound water, in $\mathrm{kJ} \cdot \mathrm{kg}^{-1}$

$\mathrm{L}$ : $\quad$ Latent heat of free water vaporization, in $\mathrm{kJ} \mathrm{kg}^{-1}$

$\mathrm{m}_{\mathrm{w}}: \quad$ Wet mass, in $\mathrm{kg}$

$\mathrm{m}_{\mathrm{anh}}: \quad$ Dry mass, in $\mathrm{kg}$

RH : $\quad$ Relative humidity, dimensionless

$\Delta \mathrm{RH}: \quad$ Incremental variation of relative humidity, dimensionless

$\mathrm{RH}_{\mathrm{amb}}$ : Ambient air relative humidity, dimensionless

$\mathrm{RH}_{\text {surf }}$ : $\quad$ Equivalent surface relative humidity, dimensionless

$\mathrm{p}_{\mathrm{v}}: \quad$ Vapor pressure, in $\mathrm{Pa}$

$\mathrm{p}_{\mathrm{vs}}: \quad \quad$ Saturated vapor pressure, in $\mathrm{Pa}$

$\mathrm{R}$ : $\quad$ Ideal gas law constant, in $\mathrm{J} \mathrm{mol}^{-1} \mathrm{~K}^{-1}$

$\mathrm{T}: \quad$ Temperature field, in $\mathrm{K}$

$\mathrm{T}_{\mathrm{amb}}$ : $\quad$ Ambient air temperature, in $\mathrm{K}$

$\mathrm{T}_{\text {surf }}$ : $\quad$ Surface temperature, in $\mathrm{K}$ 

w: $\quad$ Moisture content field, dimensionless
$\mathrm{w}_{\mathrm{i}}, \mathrm{w}_{\mathrm{i}+1}: \quad$ Incremental moisture content field, dimensionless
$\mathrm{w}_{\mathrm{S}}: \quad$ Moisture content at the fiber saturation point, dimensionless
$\mathrm{w}_{\mathrm{a}}$ : $\quad$ Moisture content field at the end of adsorption, dimensionless
$\mathrm{w}_{\mathrm{d}}$ : $\quad$ Moisture content field at the end of desorption, dimensionless

\section{Greek symbols}

$\delta: \quad \quad$ Vapor permeability, in $\mathrm{kg} \cdot \mathrm{s}^{-1} \cdot \mathrm{m}^{-1} \cdot \mathrm{Pa}^{-1}$

$\delta^{*}: \quad$ Apparent vapor permeability, in $\mathrm{kg} \cdot \mathrm{s}^{-1} \cdot \mathrm{m}^{-1} \cdot \mathrm{Pa}^{-1}$

$\delta_{\mathrm{o}}: \quad$ Vapor permeability fitting parameter, in $\mathrm{kg} \cdot \mathrm{s}^{-1} \cdot \mathrm{m}^{-1} \cdot \mathrm{Pa}^{-1}$

$\lambda(\mathrm{w}): \quad$ Thermal conductivity of the wet material, in $\mathrm{W} \cdot \mathrm{m}^{-1} \cdot \mathrm{K}^{-1}$

$\xi$ : $\quad$ Water capacity, dimensionless

$\xi_{\mathrm{a}}^{\mathrm{b}}: \quad$ Water envelope capacity in adsorption, dimensionless

$\xi_{d}^{b}: \quad$ Water envelope capacity in desorption, dimensionless

$\xi_{\mathrm{a}}: \quad$ Partial Water capacity in adsorption, dimensionless

$\xi_{\mathrm{d}}: \quad$ Partial Water capacity in desorption, dimensionless

$\rho_{\mathrm{h}}: \quad$ Wet density, in kg.m $\mathrm{m}^{-3}$

$\rho_{\text {anh }}: \quad$ Dry density, in $\mathrm{kg} \cdot \mathrm{m}^{-3}$

$\phi_{\mathrm{a}}, \alpha_{\mathrm{a}}$ : Thermodynamic parameters for adsorption, dimensionless

$\phi_{\mathrm{d}}, \alpha_{\mathrm{d}}$ : Thermodynamic parameters for desorption, dimensionless

\section{Introduction}

For both economic and environmental reasons, the use of wood in construction is of considerable interest. Due to its biological origin, timber is sensitive to external conditions. This dependence, known as hygroscopicity, induces internal moisture content by virtue of outdoor variables, including air temperature and relative humidity. Variation of mechanical properties according to moisture content is well documented for a long time. This is roughly considered in timber structures standards, with global modification factors of strength or stiffness, in supposed service classes, mostly dependent on relative humidity hypothesis. If this assumption 
is acceptable for new construction, a better knowledge of moisture content profiles in service environment is necessary for in situ assessment of existing structures. In outdoor conditions, diagnosis of structures has to balance between accuracy of prediction, and amount of data. In this paper, the specific influence of temperature on moisture transfer is studied as a guide to estimate the impact of temperature on the various steps of the hygroscopic equilibrium calculation. Prioritization and ranking of effects on a finite element model is proposed. Comparison of idealized data is provided to evaluate if the modelling is physically consistent, free from measured effects that would be difficult to model (wind-oriented airflow, enclosed fan flow, fluid/sample interactions, ...).

Two transfer laws are necessary to model the equilibrium state: Fourier's law for heat transfer, and Fick's law for moisture transfer. In addition, coupling parameters are needed to consider the thermo-migration of bound water and its dual effect. For a one-dimensional problem, these two transfer equations are as follows (Luikov, 1965; Philip and Vries, 1957):

$$
\begin{aligned}
& \frac{\partial \mathrm{T}}{\partial \mathrm{t}}=\operatorname{grad}\left[\mathrm{D}_{\mathrm{T}} \cdot \operatorname{grad}(\mathrm{T})+\mathrm{D}_{\mathrm{Tw}} \cdot \operatorname{grad}(\mathrm{w})\right] \\
& \frac{\partial \mathrm{w}}{\partial \mathrm{t}}=\operatorname{grad}\left[\mathrm{D}_{\mathrm{w}} \cdot \operatorname{grad}(\mathrm{w})+\mathrm{D}_{\mathrm{wT}} \cdot \operatorname{grad}(\mathrm{T})\right]
\end{aligned}
$$

with $D_{T}$ and $D_{w}$ respectively representing the heat and moisture transfer tensor, and $w$ the bound water content, such that:

$$
\mathrm{w}=\frac{\mathrm{m}_{\mathrm{w}}}{\mathrm{m}_{\mathrm{anh}}}
$$

with $m_{w}$ and $m_{a n h}$, respectively, the wet and dry mass. $D_{w T}$ denotes the Soret effect (Li $e t$ al., 2006; Siau, 1971; Siau and Jin, 1985a). It is used herein to model the capacity of the temperature pattern to generate a water flow. The mutual effect is represented by the parameter $D_{T w}$. While methods are indeed available to successfully measure the thermal properties of materials, determining water diffusion parameters does however remain a scientific obstacle. This determination is typically achieved using conditioning chambers so as to identify adsorption and desorption kinetics during the transitional phase. Yet as an initial constraint, this is a time-consuming method and, secondly, the application of isothermal conditions does not lead to characterizing the various thermo-hydric couplings. Tests conducted in climatic chambers also provide sorption isotherms for modeling convective transfers between air vapor and bound water on the surface of samples. Most of these isotherms are defined for a given temperature; hence, they are not directly relevant for the thermo-hydric simulation of timber structures under outdoor conditions.

The first section presents the coupled heat and mass transfer model. The coupling is proposed through Fick's and Fourier's Laws, by means of introducing internal sources led by latent heat transfers, as a result of the adsorption and desorption of bound water via a thermodynamic state change. With vapor pressure being considered as a potential activator, the equivalent relative humidity and apparent permeability are inserted into Fick's Law, as proposed by Künzel (Künzel, 1995).

The second section studies the sorption isotherms occurring in the moisture convection process both at the surface and between the inner moisture and equivalent relative humidity. Coupling 
with temperature is performed through saturation moisture and a thermodynamic sorption model.

Lastly, a parametric study is provided by way of a finite element simulation. Its objective is to display the influence of studied phenomena on the water balance and long-term trends.

\section{Coupled heat and mass transfer model}

\subsection{Constitutive law for heat transfer}

In wood, water can migrate under three different states (Stamm, 1964), see Figure 1:

- Vapor in lumens,

- Bound water in the cell wall,

- Free water over the Fiber Saturation Point.

Below the saturation point, the first two modes can coexist (Figure 1). The driving force is thus the vapor pressure gradient. An instant equilibrium between the relative humidity of air in lumens and the water bound in cells is assumed at every point of the material. This assumption neglects any convective effect on the surface of cells. However, convective effects can decelerate bound water and heat transfers between the lumens and cells. This effect will may be integrated into the characterization of the permeability coefficients.

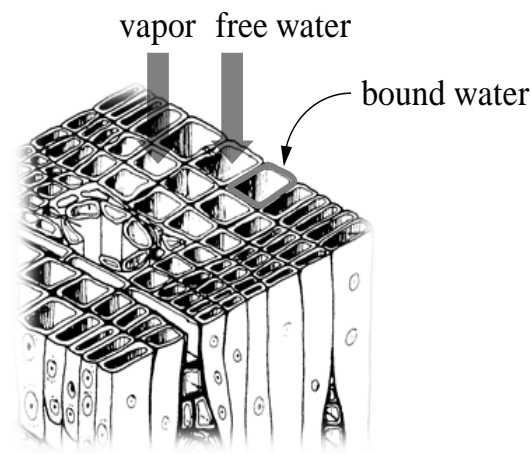

Figure 1: Three modes of water diffusion in wood

Transfer equations use two potentials, temperature $T$ and relative humidity $R H$, in conjunction with Fourier's and Fick's Laws, respectively. To introduce vapor pressure, Equation (1) is changed as shown below:

$$
\left(\rho_{\mathrm{h}} \cdot \mathrm{C}_{\mathrm{h}}\right) \cdot \frac{\partial \mathrm{T}}{\partial \mathrm{t}}=\vec{\nabla}(\lambda(\mathrm{w}) \cdot \vec{\nabla} \mathrm{T})+\mathrm{H}_{\mathrm{s}} \cdot \vec{\nabla}\left(\delta \cdot \vec{\nabla}\left(\mathrm{RH} \cdot \mathrm{p}_{\mathrm{vs}}\right)\right)
$$

Equation (4) now presents a generalized form of heat transfer, in which $\rho_{h}$ and $C_{h}$ are the density and thermal capacity, respectively, of the homogenized material composed of dry wood and bound water. According to the mixing principle, $\rho_{h}$ and $C_{h}$ are defined by the following expressions:

$$
\rho_{\mathrm{h}}=\rho_{\mathrm{anh}} \cdot(1+\mathrm{w})
$$




$$
\mathrm{C}_{\mathrm{h}}=\frac{\mathrm{C}_{\mathrm{anh}}+\mathrm{w} \cdot \mathrm{C}_{\mathrm{w}}}{1+\mathrm{w}}, \text { with } \mathrm{C}_{\mathrm{w}}=4.18 \mathrm{~kJ} \cdot \mathrm{kg}^{-1} \cdot \mathrm{K}^{-1}
$$

where $\rho_{a n h}$ and $C_{a n h}$ denote the intrinsic density and heat capacity, respectively, of dry wood. Heat transfer is governed by two thermodynamic forces: 1 ) the temperature gradient, with $\lambda$ as the thermal conductivity; and 2) the vapor pressure gradient associated with the latent heat of sorption $H_{s}$. Vapor pressure is calculated using the saturation vapor pressure $p_{v s}$ and relative humidity $R H$ of the inner air of lumens. Heat flow is proportional to vapor permeability $\delta$. Heat sorption $H_{s}$ is determined from the latent heat of free water vaporization $L$ corrected by the heat released by the fixation of water molecules bound onto fibers $\Delta H_{s}$, such that:

$$
\mathrm{H}_{\mathrm{s}}=\mathrm{L}-\Delta \mathrm{H}_{\mathrm{s}}
$$

Moreover, Merakeb (2006) proposed the following expression to relate the dependence of moisture content on sorption enthalpy:

$$
\Delta \mathrm{H}_{\mathrm{s}}=\mathrm{A} \cdot \ln \left(\frac{\mathrm{w}}{\mathrm{w}_{\mathrm{s}}}\right)
$$

$w_{s}$ indicates the moisture content when fibers are saturated by bound water for a relative humidity close to $100 \%$. $A$ is an intrinsic parameter related to each wood species; its value depends on the sorption direction, with two distinct values $A_{a}$ and $A_{d}$ for the adsorption and desorption phases, respectively (Rawat, 1996; Merakeb, 2009). Equation (8) shows that as $w$ tends toward $w_{s}$, the correction $\Delta H_{s}$ approaches 0 . Under these conditions and according to Equation (7), the latent heat of adsorption converges to the free water latent heat.

\subsection{Constitutive laws of mass transfer}

Equation (2) can be replaced by the following expression in substituting $w$ for $R H$ :

$$
\left(\rho_{\mathrm{anh}} \cdot \frac{\partial \mathrm{w}}{\partial \mathrm{RH}}\right) \cdot \frac{\partial \mathrm{RH}}{\partial \mathrm{t}}=\vec{\nabla}\left(\delta^{*} \cdot \mathrm{p}_{\mathrm{vs}} \cdot \vec{\nabla} \mathrm{RH}\right)+\vec{\nabla}\left(\delta \cdot \mathrm{RH} \cdot \vec{\nabla} \mathrm{p}_{\mathrm{vs}}\right)
$$

$\rho_{\text {anh }}$ is the anhydrous density of the material. $\delta^{*}$ denotes the apparent permeability, which integrates the permeability vapor and a correction dependent on moisture content. Choong (1963), Kulasinski (2015), Rosen (1976) and Stamm (1959, 1964) have all observed that the permeability coefficient is an increasing function with respect to temperature. They have proposed correlating this increase via an Arrhenius Law, which typically describes the influence of temperature on chemical reaction kinetics according to both the activation energy and the ideal gas law constant. In our case, the Arrhenius Law can be used to express permeability in the following form:

$$
\delta^{*}=\delta_{\mathrm{o}} \cdot \exp \left(-\frac{\mathrm{E}_{\mathrm{a}}}{\mathrm{R} \cdot \mathrm{T}}\right)
$$


$\delta_{O}$ is a virtual permeability value which can be defined as a fitting parameter. $T$ is the temperature given in Kelvin, $R$ the ideal gas constant, and $E_{a}$ the activation energy. According to Nelson (1986, 1991), Siau (1985b) and Skaar (1988), the activation energy $E_{a}$ depends on both sorption latent heat and the specific heat capacity of vapor $C_{p_{v}}$, such that:

$$
\mathrm{E}_{\mathrm{a}}=\mathrm{H}_{\mathrm{s}}-\left(\mathrm{C}_{\mathrm{p}_{\mathrm{v}}} \cdot \mathrm{T}\right)
$$

In considering Equation (11), the apparent permeability $\delta^{*}$, as defined in Equation (10), becomes:

$$
\delta^{*}=\delta_{\mathrm{o}} \cdot \exp \left(-\frac{\mathrm{H}_{\mathrm{s}}-\left(\mathrm{C}_{\mathrm{p}_{\mathrm{V}}} \cdot \mathrm{T}\right)}{\mathrm{R} \cdot \mathrm{T}}\right)
$$

\subsection{Boundary conditions}

Heat and mass transfer must be completed by heat and water transfers at the surface. Such transports are expressed by the following differential equations:

$$
\begin{gathered}
\lambda \cdot \frac{\partial \mathrm{T}}{\partial \mathrm{x}}=\mathrm{h}_{\mathrm{T}} \cdot\left(\mathrm{T}_{\mathrm{amb}}-\mathrm{T}_{\text {surf }}\right) \\
\delta \cdot \frac{\partial \mathrm{Rh}}{\partial \mathrm{x}}=\mathrm{h}_{\mathrm{w}} \cdot\left(\mathrm{RH}_{\mathrm{amb}}-\mathrm{RH}_{\text {surf }}\right)
\end{gathered}
$$

where $\delta$ designates permeability. The values $\left(T_{a m b}, R H_{a m b}\right)$ and $\left(T_{\text {surf }}, R H_{\text {surf }}\right)$ denote the mean temperature and relative humidity of ambient air and sample surface, respectively. The heat and water flows are thus proportional to the coefficients of surface heat and water transfers, $h_{T}$ and $h_{w}$.

\section{Sorption isotherms}

As regards model implementation in the context of structural timber behavior, the three difficulties yet to be overcome consist of: the isotherm envelope, partial hysteresis, and temperature dependence.

\subsection{Isotherm envelopes}

Hygroscopic materials can adsorb or desorb water molecules when placed in wet or dry environments, resulting in transports between bound water and water vapor present in the surrounding air. On the material surface, this process acts as the engine of convective transfers. Moreover, in the material, it characterizes the transport of water molecules between porosities and sorption sites, thus inducing energy transfers due to the creation or rupture of hydrogen bonds between bound water and material fibers. Several models have been proposed in the literature. While most have been developed on the basis of phenomenological hypotheses (Brunauer et al., 1938; Dent, 1980; Hartley, 1993; Stamm, 1964), others are based on thermodynamic approaches. Among this latter category, Merakeb (2006) interpreted hygroscopic balance as a thermodynamic property of bound water. By analogy with the latent heat of free water vaporization, the following form has been proposed: 


$$
\Delta \mathrm{H}_{\mathrm{s}}=\mathrm{R} \cdot \mathrm{T}^{2} \cdot\left(\frac{\partial \ln \left(\mathrm{p}_{\mathrm{v}}\right)}{\partial \mathrm{T}}-\frac{\partial \ln \left(\mathrm{p}_{\mathrm{vs}}\right)}{\partial \mathrm{T}}\right)=\mathrm{R} \cdot \mathrm{T}^{2} \cdot \frac{\partial \ln (\mathrm{RH})}{\partial \mathrm{T}}
$$

In considering Equations (8) and (15), Merakeb developed a logarithmic relationship of the following general form between water content and relative humidity:

$$
\ln \left(\frac{\mathrm{w}}{\mathrm{w}_{\mathrm{S}}}\right)=\phi_{\mathrm{i}} \cdot \ln (\mathrm{RH}) \cdot \exp \left(\alpha_{\mathrm{i}} \cdot \mathrm{RH}\right)
$$

$\phi_{i}$ and $\alpha_{i}$ refer to two specific parameters for adsorption $\left(\phi_{a}, \alpha_{a}\right)$ and desorption $\left(\phi_{d}, \alpha_{d}\right)$. This duplication serves to translate the hysteretic effects discussed by Chen et al. (2018) about the hysteresis mechanism connected with the different hydrogen bond network. The relevance of the model compared to gravimetric tests conducted at $23^{\circ} \mathrm{C}$ for Douglas fir wood is highlighted Figure 2, as proposed in Merakeb (2006).

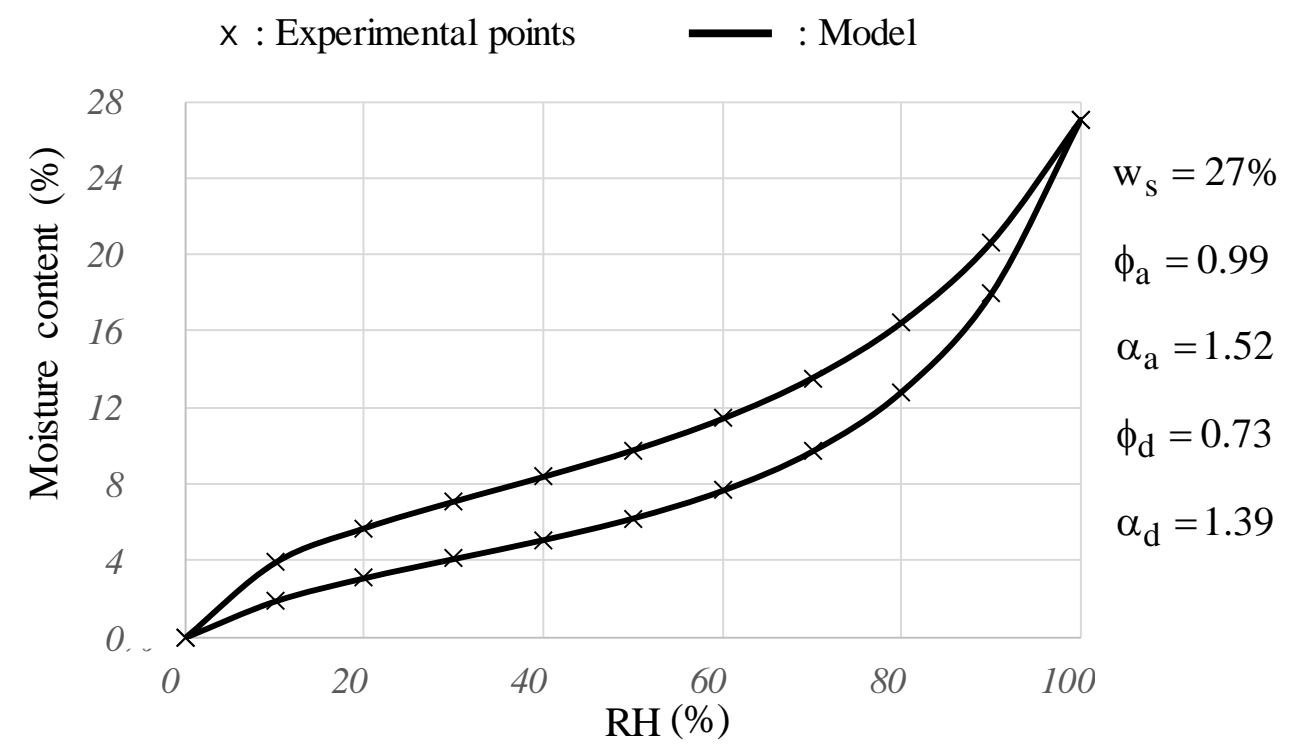

Figure 2: Sorption hysteresis, model vs. experimental results for Douglas fir wood

\subsection{Partial isotherms}

Buildings exposed to outdoor conditions are not subjected to total moisture cycles from $0 \%$ to $100 \%$ RH. Sorption hysteresis must therefore be replaced by partial isotherms. Carsten-RodePedersen (1990), Kulasinski (2015) and Merakeb (2006) suggested a model that takes into account water capacity $\xi$, as defined by:

$$
\xi=\frac{\partial \mathrm{w}}{\partial \mathrm{RH}}
$$

Under these conditions, with $w_{i}$ being the initial water content for relative humidity $R H_{i}$, two water capacities can be defined as follows: 


$$
\xi_{d}=\frac{\left(w_{i}-w_{a}\right)^{\beta} \cdot \xi_{d}^{b}+D \cdot\left(w_{d}-w_{i}\right)^{\beta} \cdot \xi_{a}^{b}}{\left(w_{d}-w_{a}\right)^{\beta}}
$$

and

$$
\xi_{a}=\frac{A \cdot\left(w_{i}-w_{a}\right)^{\beta} \cdot \xi_{d}^{b}+\left(w_{d}-w_{i}\right)^{\beta} \cdot \xi_{a}^{b}}{\left(w_{d}-w_{a}\right)^{\beta}}
$$

Equations (18) and (19) have been integrated into an explicit incremental algorithm in order to calculate the equilibrium humidity for relative humidity $R H_{i+1}\left(R H_{i+1}=R H_{i}+\Delta R H\right)$. In this case, $w_{a}$ and $w_{d}$ represent the moisture values projected onto the adsorption and desorption isotherm envelope, respectively, for $R H_{i+1}$ calculated using Equation (16). $\xi_{a}^{b}$ and $\xi_{d}^{b}$ denote the water capacities of the isotherm envelope calculated by derivation of Equation (16). $A, D$ and $\beta$ are three phenomenological parameters. Hence, by applying Equations (18) and (19), an update of internal humidity $w_{i+1}$ is expressed as follows:

$$
\mathrm{w}_{\mathrm{i}+1}=\xi_{\mathrm{a}, \mathrm{d}} \cdot \Delta \mathrm{RH}+\mathrm{w}_{\mathrm{i}}
$$

To illustrate this approach, the model response is compared to Merakeb's experimental results. In his work, Merakeb proposed a cyclic sorption test with a decreasing amplitude centered at: $50 \%$ RH (0\%-100\%, 100\%-20\%, 20\%-80\%, 80\%-30\%, 30\%-70\%, 70\%-40\%, 40\%-60\%, 60\%$50 \%$, Figure 3).
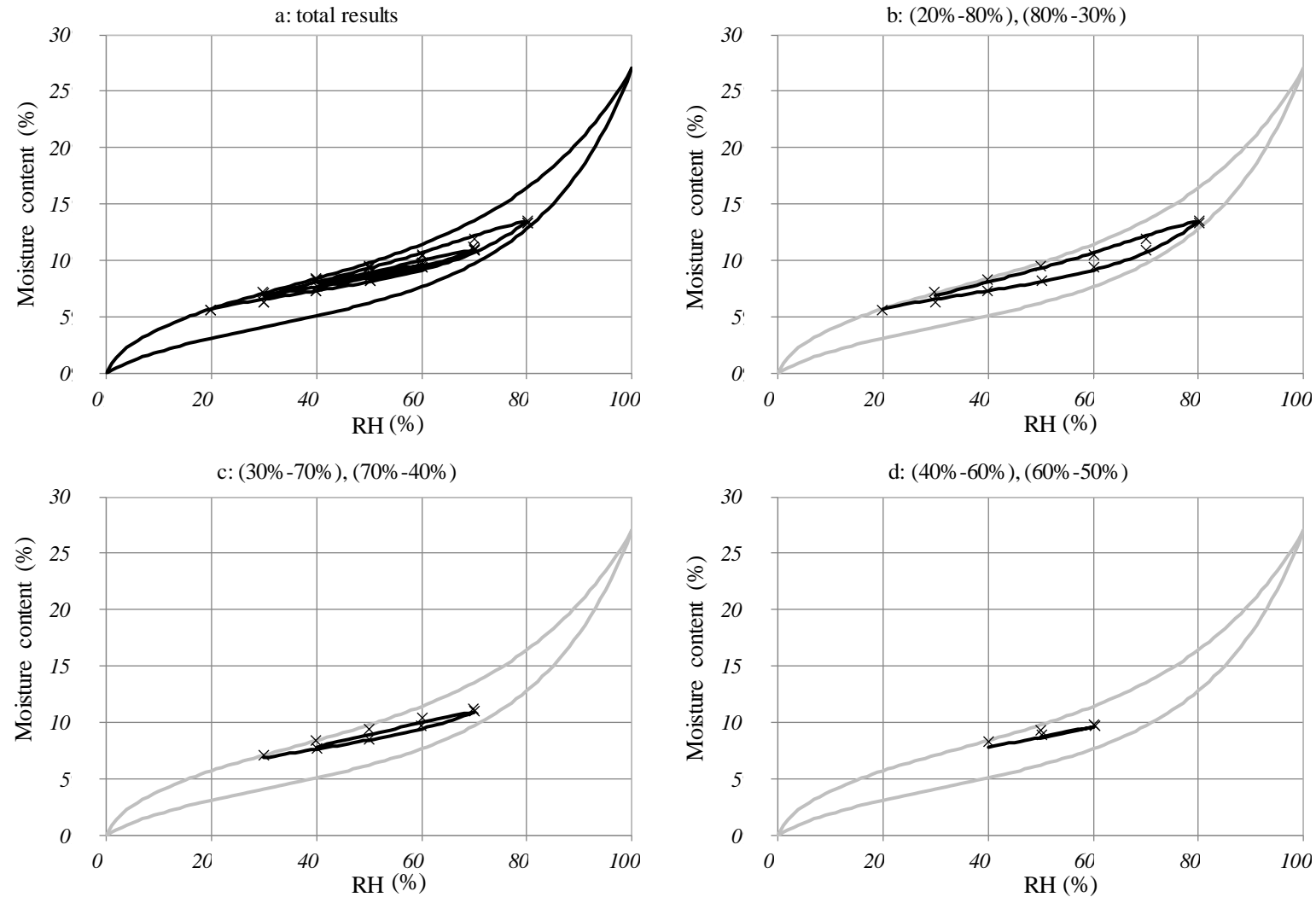

Figure 3: Partial isotherms, model vs. experimental results 
The simulation was performed with an increment of $1 \%$ relative humidity according to the following parameter values:

$$
\mathrm{A}=0.4, \mathrm{D}=0.06 \text { and } \beta=1.5
$$

A good fit has been obtained between the model and experimental test results, with a slightly increasing relative error, yet not exceeding a least square error of $1.8 \%$ for the last cycle.

\subsection{Temperature dependence}

In the literature, many studies on sorption isotherms have been carried out under isothermal conditions. Nonetheless, it is accepted that the water balance is conditioned by the ambient temperature. Some authors (Merakeb et al., 2009; Perré and May, 2001) have proposed an initial correction that strongly affects the moisture content at $100 \%$ relative humidity, the fiber saturation point $w_{s}$. From a phenomenological standpoint, a linear dependence on temperature is proposed, i.e.:

$$
\mathrm{w}_{\mathrm{S}}=0,598-10^{-3} \cdot \mathrm{T}
$$

In agreement with Frandsen (2007), this question is being raised here from the perspective of thermodynamic transfers, whose temperature constitutes a catalyst according to Le Chatelier's principle. Let's consider a temperature increase $\Delta T$. The induced heat variation is given by:

$$
\mathrm{dE}=\mathrm{m}_{\mathrm{h}} \cdot \mathrm{C}_{\mathrm{h}} \cdot \mathrm{dT}
$$

where $m_{h}$ is the homogenized mass sample, composed of dry mass $m_{a n h}$ and bound water mass $m_{w}$, whereby:

$$
\mathrm{m}_{\mathrm{h}}=\mathrm{m}_{\mathrm{anh}}+\mathrm{m}_{\mathrm{w}}
$$

This heat variation is balanced with the sorption process. Equations (7), (8) and (23) can now be used to write the following at the saturation point $\left(\mathrm{w}=\mathrm{w}_{\mathrm{s}}\right)$ :

$$
\left(\mathrm{m}_{\mathrm{anh}} \cdot \mathrm{C}_{\mathrm{anh}}+\mathrm{m}_{\mathrm{w}} \cdot \mathrm{C}_{\mathrm{w}}\right) \cdot \mathrm{dT}=-\mathrm{L} \cdot \mathrm{dm}_{\mathrm{w}}
$$

In considering Equation (3), Equation (24) is laid out as a first-order differential equation:

$$
\frac{\mathrm{dw}_{\mathrm{s}}}{\mathrm{dT}}+\frac{\mathrm{C}_{\mathrm{w}}}{\mathrm{L}} \cdot \mathrm{w}_{\mathrm{s}}=-\frac{\mathrm{C}_{\mathrm{anh}}}{\mathrm{L}}
$$

Heat capacity of bound water can change, as recently described in Zhang (2020). For a civil engineering application, for moisture and thermal ranges, the heat capacities $C_{a n h}$ and $C_{w}$ as well as latent water vaporization heat $L$ are assumed as invariant relative to ambient temperature. An analytical form of saturation humidity as a function of temperature is thus derived by solving Equation (25), i.e.:

$$
\mathrm{w}_{\mathrm{s}}(\mathrm{T})=\left(\mathrm{w}_{\mathrm{s}}^{\mathrm{o}}+\frac{\mathrm{C}_{\mathrm{anh}}}{\mathrm{C}_{\mathrm{w}}}\right) \cdot \exp \left(-\frac{\mathrm{C}_{\mathrm{w}}}{\mathrm{L}} \cdot(\mathrm{T}-273)\right)-\frac{\mathrm{C}_{\mathrm{anh}}}{\mathrm{C}_{\mathrm{w}}}
$$


where $w_{s}^{o}$ is the saturation moisture at $273 \mathrm{~K}$. The proposed analytical model has been compared to the data stemming from both the hygroscopic equilibrium abacus of Eurocode 5 (AFNOR, 2010) and the linearized function proposed by Perré, (see Equation (21)), yielding a very good correlation (Fig. 4) with the following thermodynamic parameters:

$$
\mathrm{L}=2500 \mathrm{~kJ} \cdot \mathrm{kg}^{-1}, \mathrm{C}_{\mathrm{anh}}=1600 \mathrm{~J} \cdot \mathrm{kg}^{-1} \cdot \mathrm{K}^{-1} \text { and } \mathrm{C}_{\mathrm{W}}=4180 \mathrm{~J} \cdot \mathrm{kg}^{-1} \cdot \mathrm{K}^{-1}
$$

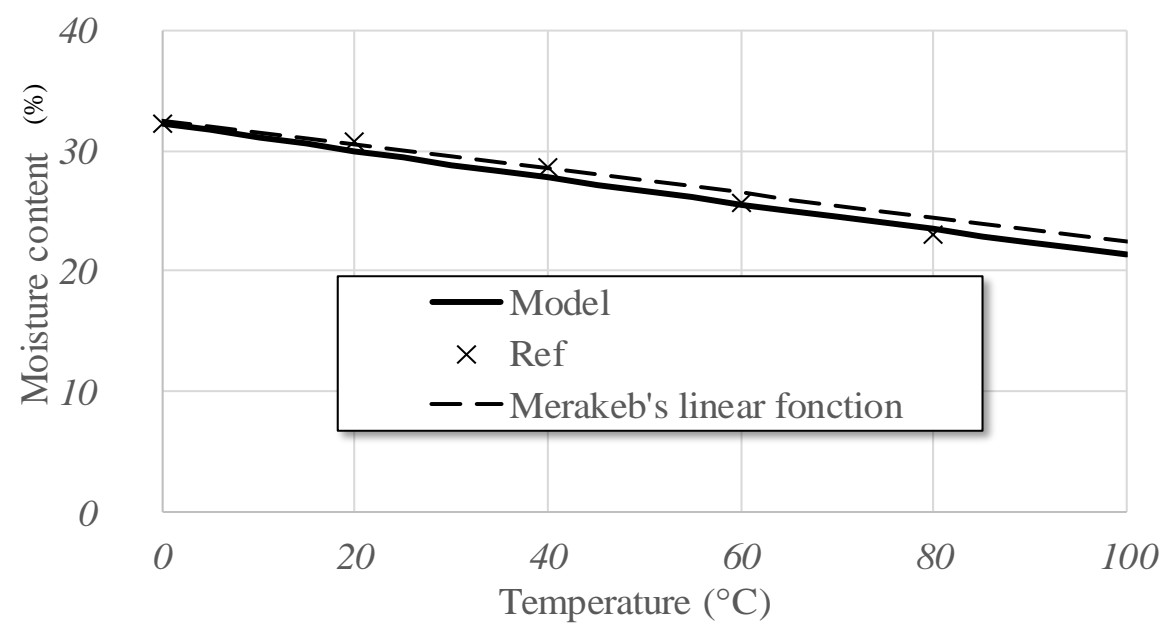

Figure 4: Saturation moisture content as a function of temperature

\section{Simulation and discussion}

In order to estimate the thermo-hydric coupling and hysteresis effects on heat and mass transfer, a parametric study will be proposed in this section. The moisture diffusion direction is confined to the grain's direction when considering a 3D model whose general algorithm is implemented in the finite element code CASTEM. The wood species studied is a Douglas fir, i.e. Pseudotsuga menziesii.

\subsection{Geometry and boundary conditions}

The geometry and boundary conditions of this study are described in Figure 5. Four sides are moisture-proof while being permeable to heat flow. Only the two faces perpendicular to fibers are conducive to heat and moisture convective transfers. The mesh discretizes the $8^{\text {th }}$ volume.

According to Equations (13) and (14), the convection process is driven by $h_{t}$ and $h_{w}$. Heat flow is assumed to be isotropic. For forced convection conditions, these values are fixed to:

$$
\mathrm{h}_{\mathrm{t}}=9 \mathrm{~W} \cdot \mathrm{m}^{-2} \cdot \mathrm{K}^{-1} \text { and } \mathrm{h}_{\mathrm{w}}=3,75 \cdot 10^{-8} \mathrm{~s} \cdot \mathrm{m}^{-1}
$$

For an initial conditioning with a temperature of $20^{\circ} \mathrm{C}$ and relative humidity of $60 \%$, the initial and homogeneous internal moisture has been calculated at $11.7 \%$. 


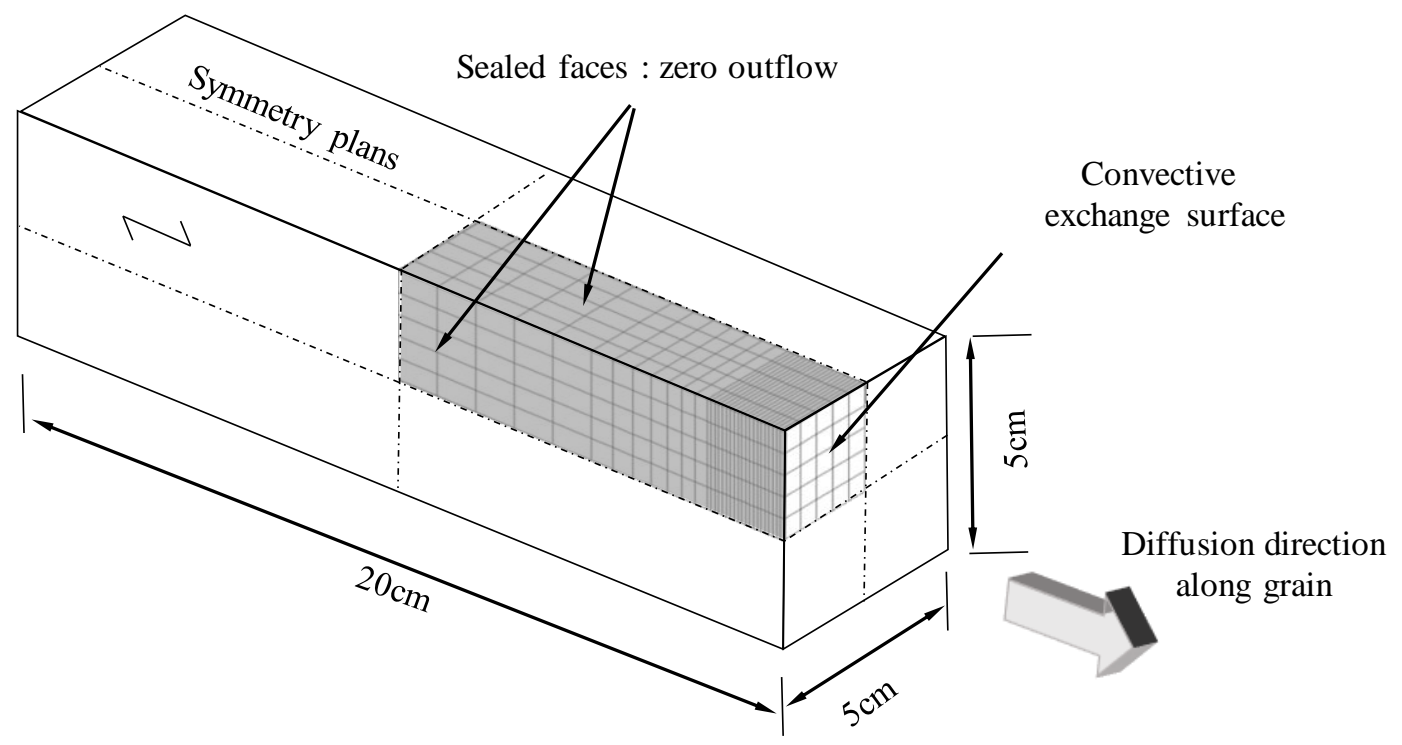

Figure 5: Geometry sample, finite element mesh and boundary conditions

\subsection{Climate stressors}

In order to simulate an average European oceanic climate, an annual climate is created. This input is closed to exterior recording. Reproduced fifty times, its periodicity assists comparison between simulations options. Temperature and relative humidity functions, representing seasonal changes (over 360 days), anticyclonic effects (15 days) and daily variations (1 day) in both temperature and relative humidity, have been assigned as follows:

$$
\begin{aligned}
\mathrm{RH}(\mathrm{t}) & =\operatorname{MIN}\left(1 ; \overline{\mathrm{RH}}+\sum_{\mathrm{i}=1}^{3} \mathrm{RH}_{\mathrm{i}} \cdot \sin \left(\frac{2 \cdot \pi}{\mathrm{P}_{\mathrm{i}}} \cdot \mathrm{t}-\varphi_{\mathrm{i}}^{\mathrm{Rh}}\right)\right) \\
\mathrm{T}(\mathrm{t}) & =\operatorname{MAX}\left(0 ; \overline{\mathrm{T}}+\sum_{\mathrm{i}=1}^{3} \mathrm{~T}_{\mathrm{i}} \cdot \sin \left(\frac{2 \cdot \pi}{\mathrm{P}_{\mathrm{i}}} \cdot \mathrm{t}-\varphi_{\mathrm{i}}^{\mathrm{T}}\right)\right)
\end{aligned}
$$

The climatic amplitudes are specified in Table 1. The temporal evolution of the relative humidity is in phase opposition with temperature for the annual, sequential and daily periods (i.e. $\left.\varphi_{i}^{R H}=\varphi_{i}^{T}+\pi\right)$. While the sequential and daily phase shifts are zero in temperature, the annual temperature phase shift corresponds to the first day of simulation positioned during the year. Moreover, the evolution of the relative humidity is limited between $0 \%$ and $100 \% \mathrm{RH}$, and temperature is limited to positive values.

Table 1: Climatic amplitudes

\begin{tabular}{lccc}
\hline & Annual & Sequential & Daily \\
\hline $\mathrm{RH}$ & $\mathrm{RH}_{1}$ & $\mathrm{RH}_{2}$ & $\mathrm{RH}_{3}$ \\
& $15 \%$ & $20 \%$ & $10 \%$ \\
\hline $\mathrm{T}$ & $\mathrm{T}_{1}$ & $\mathrm{~T}_{2}$ & $\mathrm{~T}_{3}$ \\
& $12.5^{\circ} \mathrm{C}$ & $5^{\circ} \mathrm{C}$ & $5^{\circ} \mathrm{C}$ \\
\hline
\end{tabular}


Lastly, the average values of the cycles are $\overline{\mathrm{RH}}=65 \%$ and $\overline{\mathrm{T}}=13.3^{\circ} \mathrm{C}$. An example is provided in Figure 6, showing the annual change in temperature and humidity with an origin in mid-season before the hot dry period $\left(\varphi_{1}^{\mathrm{T}}=\pi\right)$. This simulation begins at a time when the external conditions are close to the internal equilibrium value.

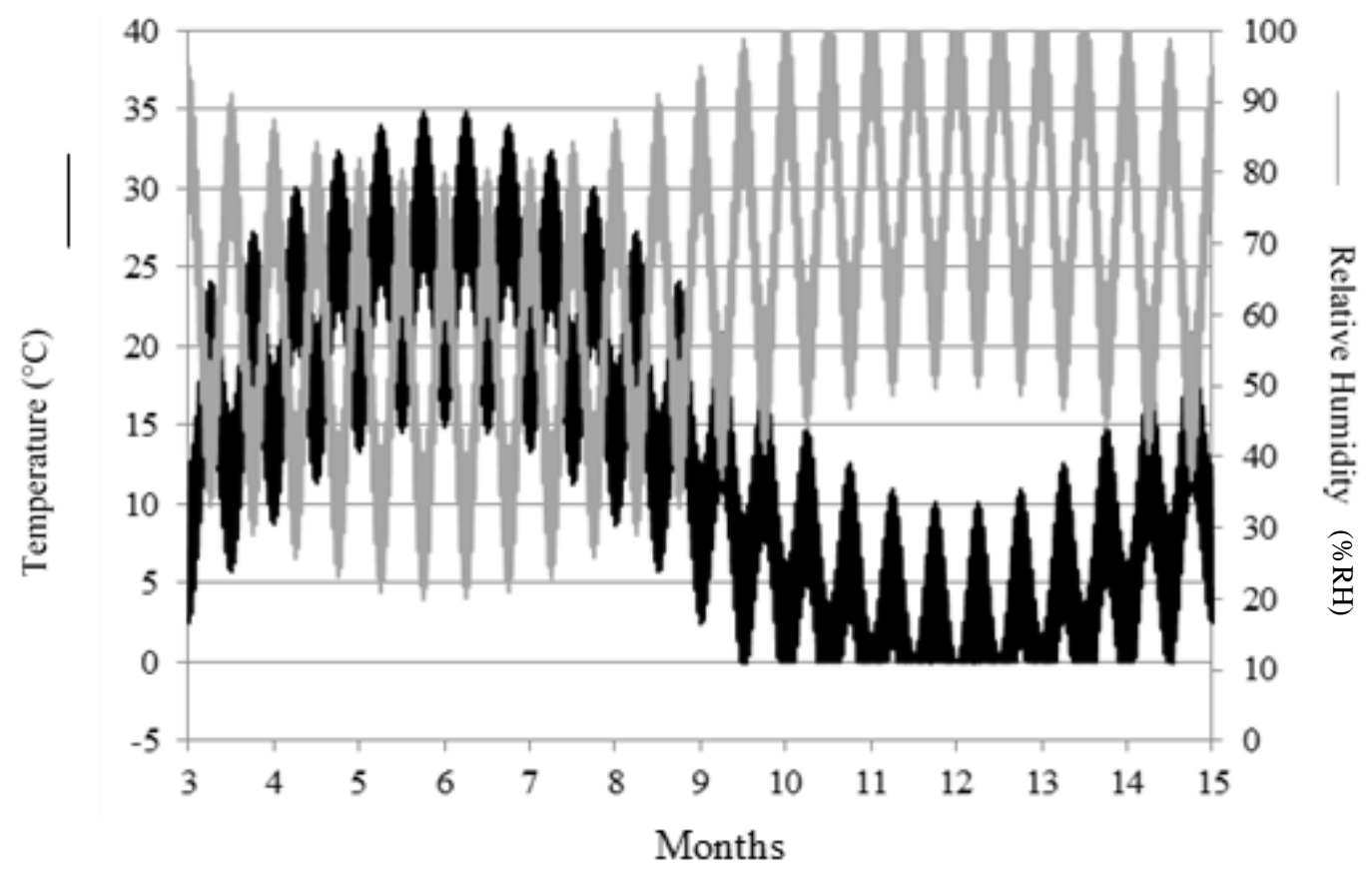

Figure 6: Temporal evolution of temperature and humidity over one year

\subsection{Diffusion properties and isotherms}

According to the previous description, experimental identification of parameters on Douglas fir is presented in Varnier et al.(2018). The diffusion properties are specified in The parameters of the total and partial adsorption and desorption isotherms are presented in Table 3.

Table 2. The parameters of the total and partial adsorption and desorption isotherms are presented in Table 3.

Table 2: Diffusion properties in the longitudinal direction (Douglas fir)

\begin{tabular}{cccccc}
\hline$\delta_{\mathrm{o}}$ & $\rho_{\mathrm{anh}}$ & $\mathrm{C}_{\mathrm{anh}}$ & $\lambda(\mathrm{w})$ & $A_{a}$ & $A_{d}$ \\
\hline $15 \cdot 10^{-4}$ & 450 & 1.6 & $0.17 \cdot \mathrm{w}+0.28$ & -0.36 & -0.58 \\
\hline
\end{tabular}

Table 3: Partial and total isotherms parameters (Douglas fir)

\begin{tabular}{cccccccc}
\hline $\mathrm{w}_{\mathrm{s}}\left(\mathrm{T}=0^{\circ} \mathrm{C}\right)$ & $\phi_{\mathrm{a}}$ & $\phi_{\mathrm{d}}$ & $\alpha_{\mathrm{a}}$ & $\alpha_{\mathrm{d}}$ & $\mathrm{A}$ & $\mathrm{D}$ & $\beta$ \\
\hline $29.4 \%$ & 0.82 & 0.76 & 1.44 & 0.99 & 0.4 & 0.06 & 1.5 \\
\hline
\end{tabular}

\subsection{Calculation hypotheses}

In order to highlight the contributions of the proposed model compared to more typical approaches, eight simulation variants have been assessed. 
The following parameters vary over the 8 studied combinations (Table 4):

- Influence of temperature on apparent permeability according to Arrhenius' Law

- Influence of temperature on the saturation water content according to Le Chatelier's principle

- Influence of sorption hysteresis through partial isotherms according to Pedersen's model. If hysteresis is neglected, then the median sorption curve is used.

When a variant fails to consider the influence of temperature on one of the parameters, it is determined for a temperature of $20^{\circ} \mathrm{C}$.

Table 4: Coding of the 8 combinations

\begin{tabular}{lccc}
\hline & $\delta=f(\mathrm{~T})$ & $\mathrm{w}_{\mathrm{s}}=\mathrm{f}(\mathrm{T})$ & Hysteresis \\
\hline Case 1 & No & No & No \\
Case 2 & No & No & Yes \\
Case 3 & No & Yes & No \\
Case 4 & No & Yes & Yes \\
Case 5 & Yes & No & No \\
Case 6 & Yes & No & Yes \\
Case 7 & Yes & Yes & No \\
Case 8 & Yes & Yes & Yes \\
\hline
\end{tabular}

\subsection{Results and analysis}

The average inner moisture evolution over 5 years is presented in Figure 7 for these 8 combinations.

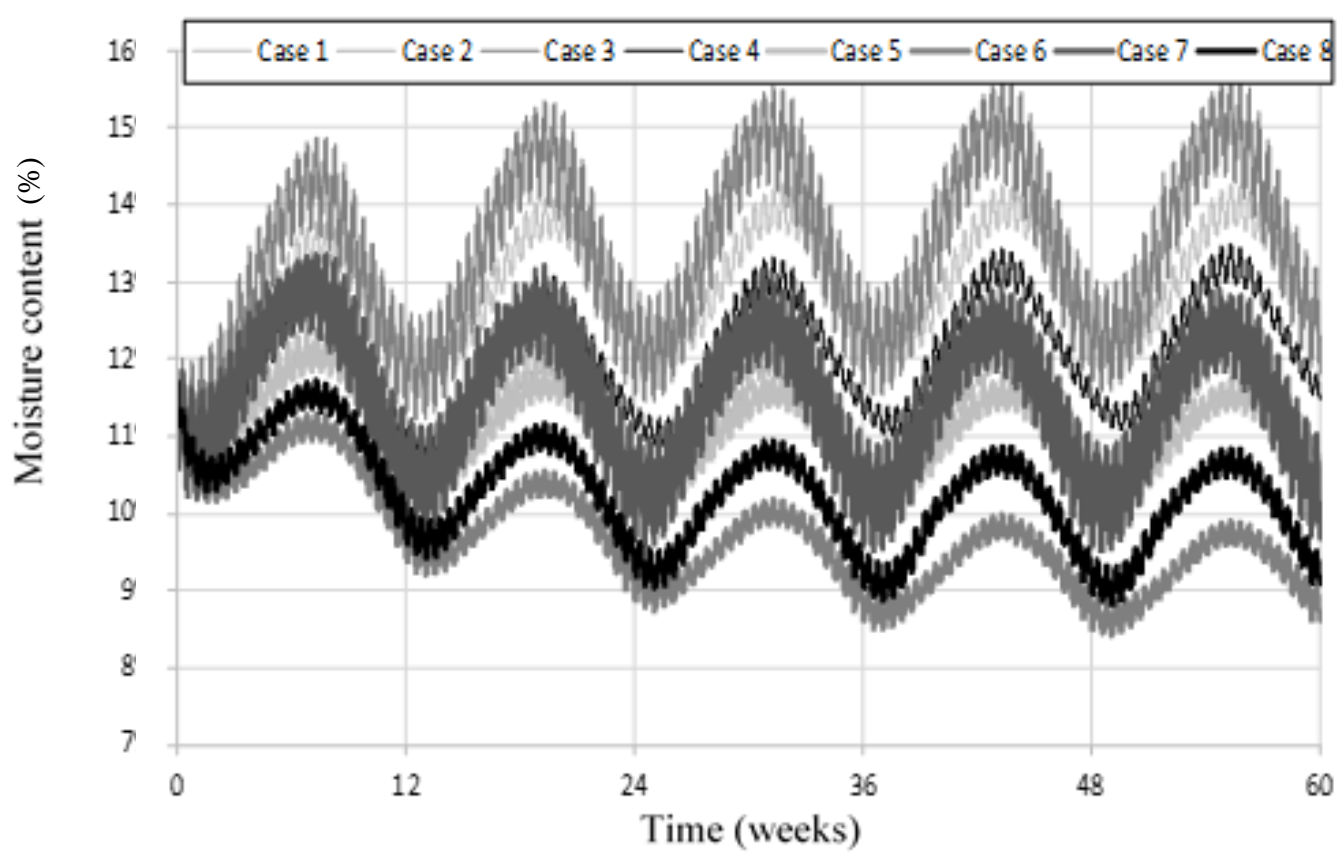

Figure 7: Average inner moisture evolution 
The difference between results can now be analyzed from several standpoints.

- Deviation from a reference

Setting as a reference the variant with the most temperature-dependent parameters (case 8), the evolution of differences between the other 7 cases and the reference is plotted in Figure 8:

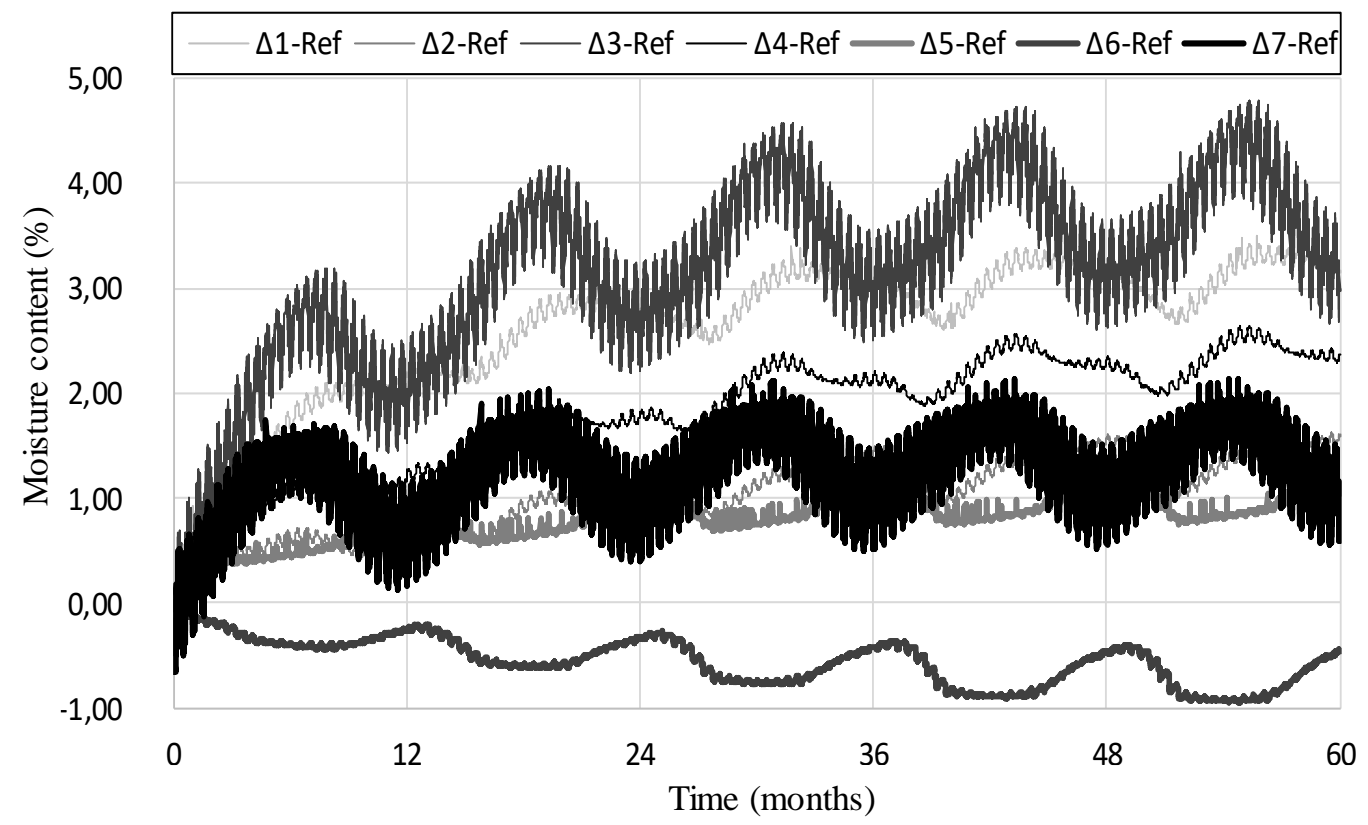

Figure 8: Evolution of deviations from the reference case (i.e. case 8)

An initial conclusion can be drawn from the influence of the three phenomena on the average moisture content. Except for case 6, the other cases have all overestimated this influence. The variation compared to case 3 indicates the greatest overestimation, i.e. up to $4.5 \%$ of moisture content.

This general overview however is too broad to isolate the impact of each individual parameter, whose impact on inner moisture will now be analyzed.

- Influence of hysteresis

The influence of hysteresis is visible in Figure 9 by comparing models 1/2, 3/4, 5/6 and 7/8 in pairs.

These differences reveal a 5-year equilibrium between $0.5 \%$ and $2 \%$ moisture content. Thus, neglecting the effect of hysteresis induces an overestimation of the water balance.

Moreover, the representation $\Delta 1-2$ and $\Delta 5-6$ highlights the influence of hysteresis on diffusion kinetics. Indeed, the hygroscopic equilibrium is reached more quickly on those models that do not take the influence of temperature on permeability into account. 


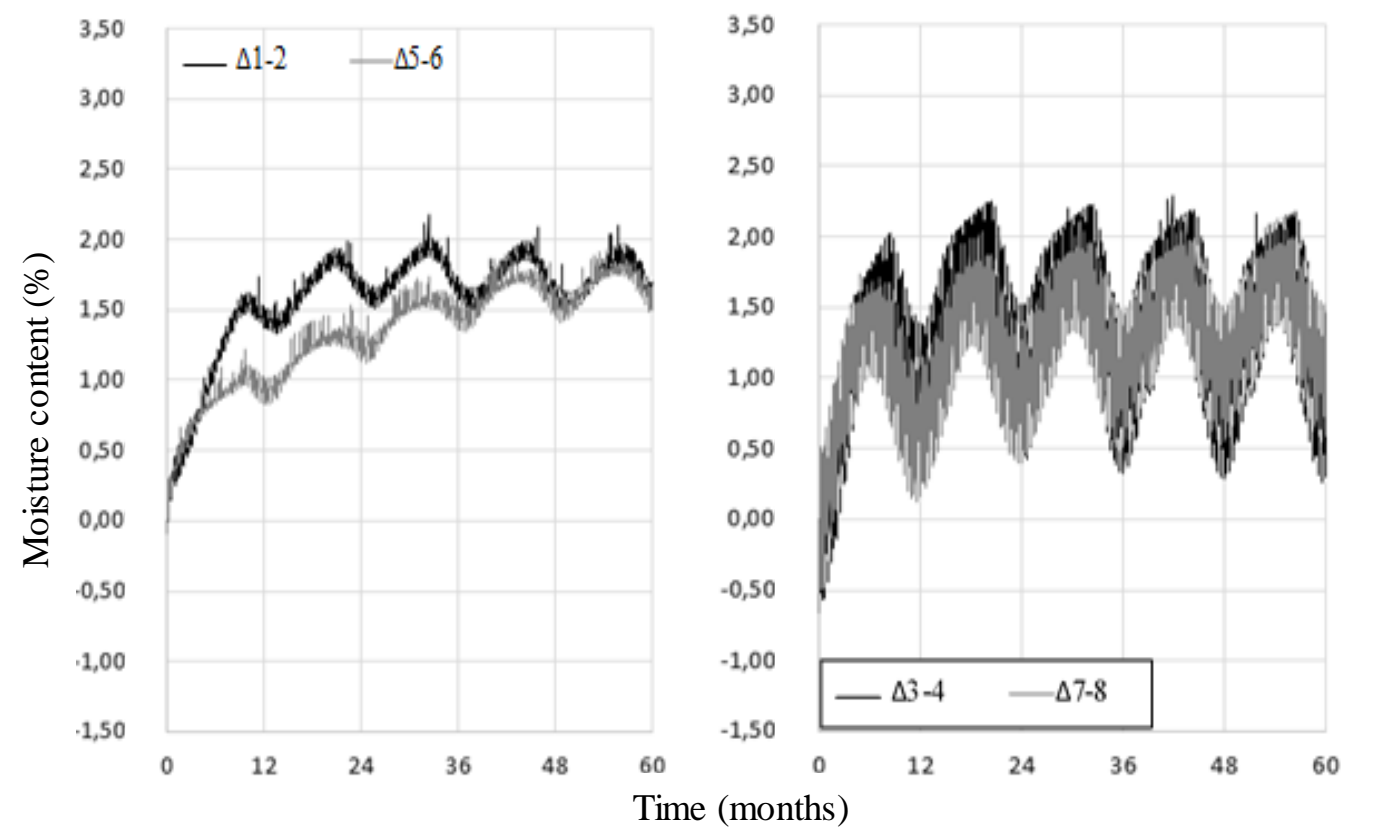

Figure 9: Differences between cases in which hysteresis is considered or not

- Influence of temperature on $w_{s}$

The dependence of temperature on $w_{s}$ is exposed by comparing models $2 / 4,6 / 8,1 / 3$ and $5 / 7$ two-by-two (Figure 10):

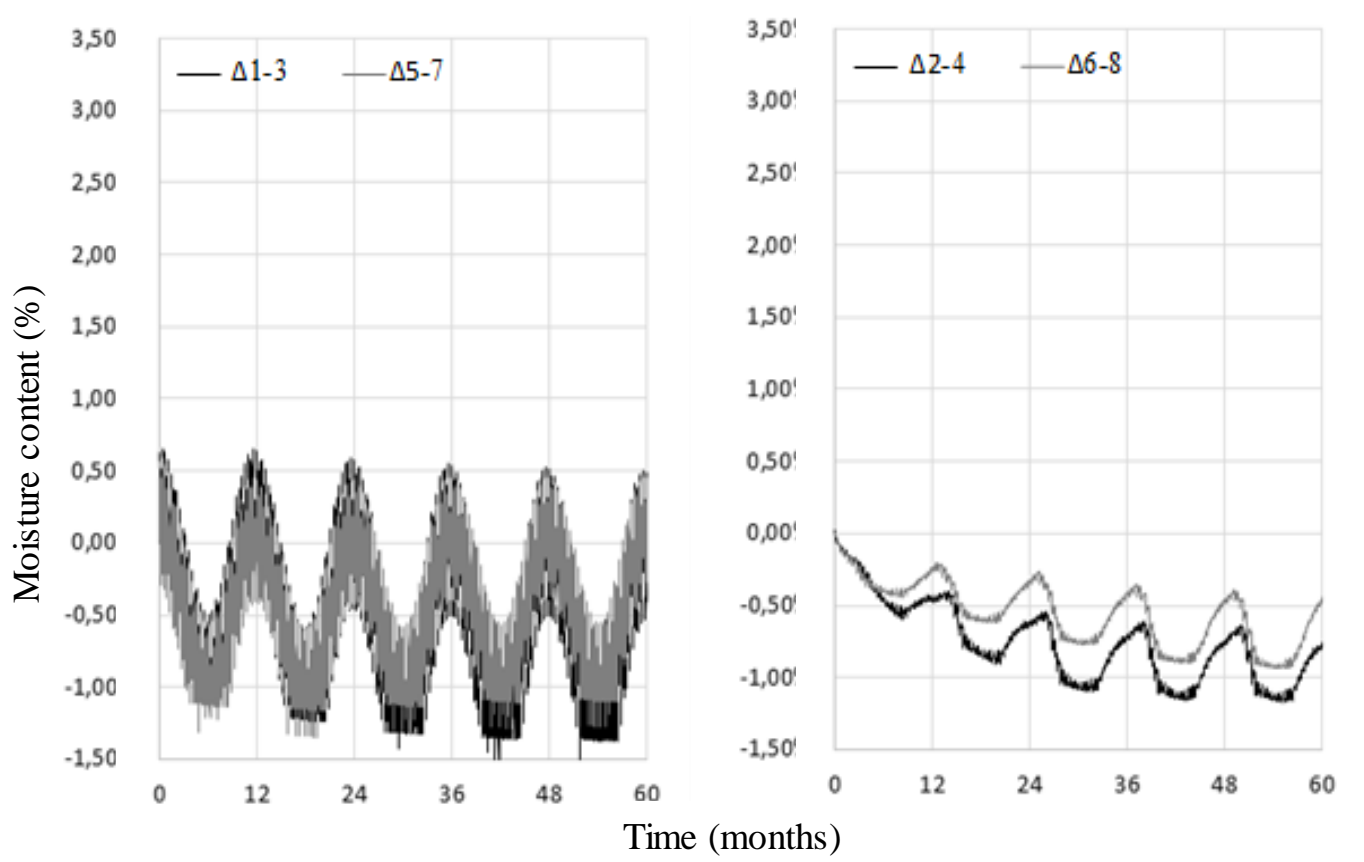

Figure 10: Differences between cases in which $\mathrm{w}_{\mathrm{s}}$ is dependent or not on temperature

Deviation trends point to a 5 -year equilibrium between $+0.5 \%$ and $-1.5 \%$ moisture content. Hence, discounting temperature dependence on $w_{s}$ induces an underestimation of the water balance. 
Couples 2-4 and 6-8 also highlight the influence the role of temperature dependence in the relationship between apparent permeability and hygroscopic equilibrium.

- Influence of temperature on permeability

The four differences all generally exhibit the same behavior, which suggests that the temperature dependence of permeability exerts the greatest impact on the evolution of $w$. Moreover, neglecting the influence of temperature on the apparent permeability yields an overestimation of average humidity by $2-2.5 \%$.

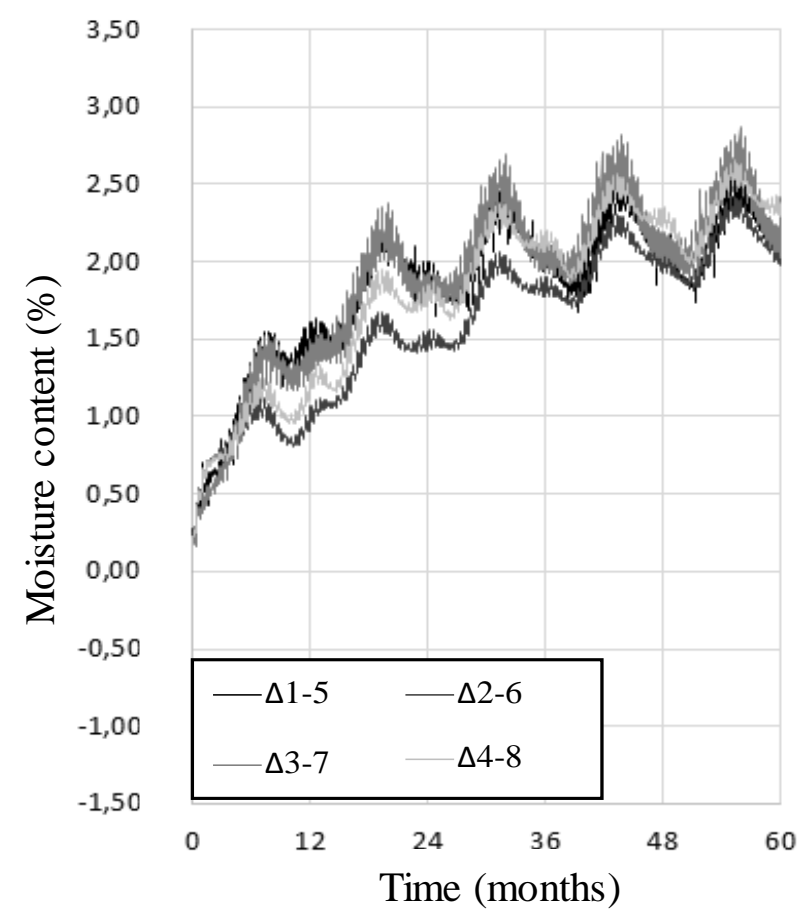

Figure 11: Differences between cases where the influence of temperature on permeability is taken into consideration or not

- Beginning and end of period

The average moisture differences for the 8 cases during the first and last weeks of simulation are presented in Figure 12.

Cases 3 and 7 are the only ones to show average moisture changes over a daily period. These variations are on the order of $0.75 \%$ water content. Hence, the other six cases are only sensitive to sequential trends. After 5 years, the hygroscopic equilibrium of all 8 cases varies over an interval ranging from $8.75 \%$ to $12.25 \%$ water content. 


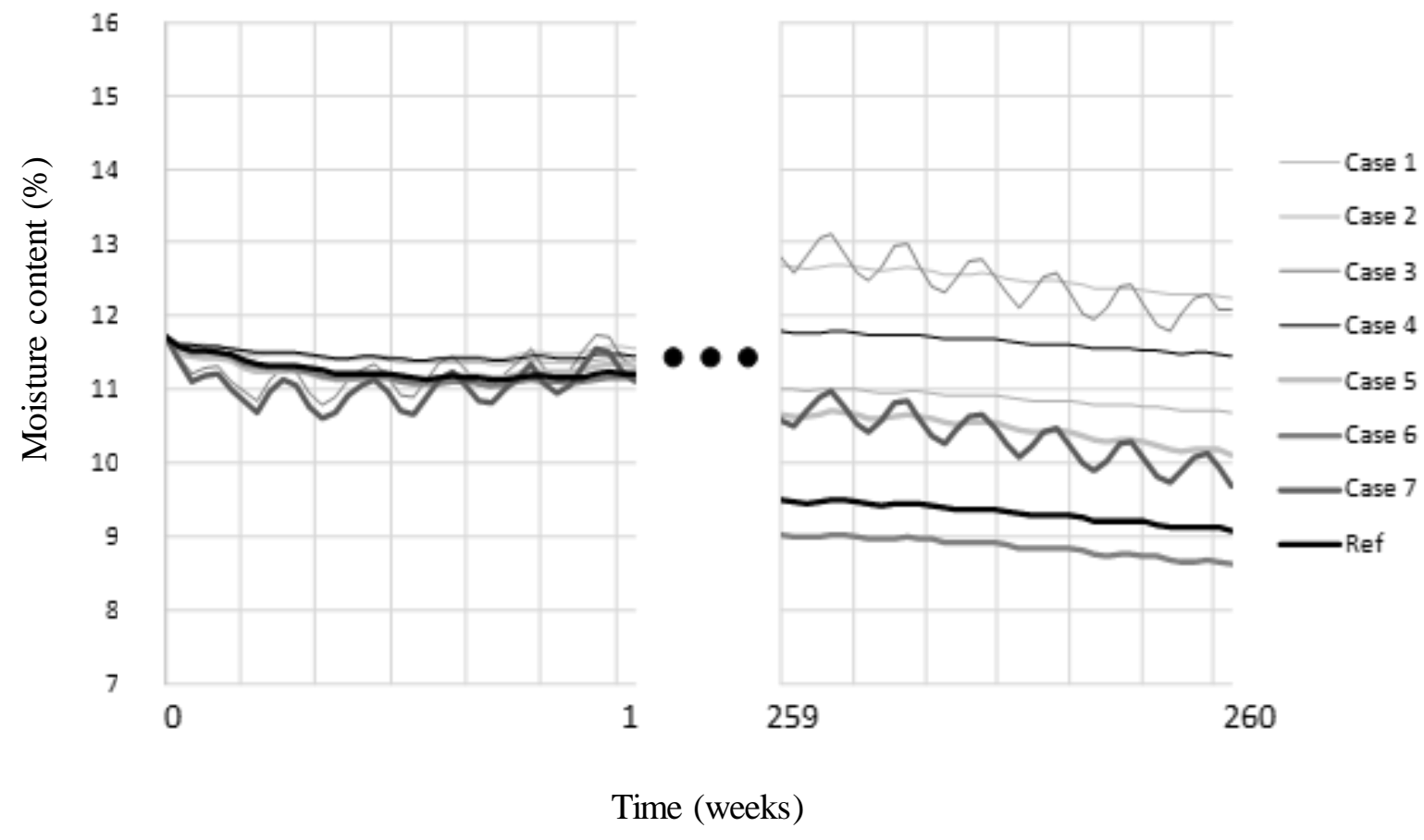

Figure 12: Evolution in inner moisture for the first and last weeks of the 5-year simulation period
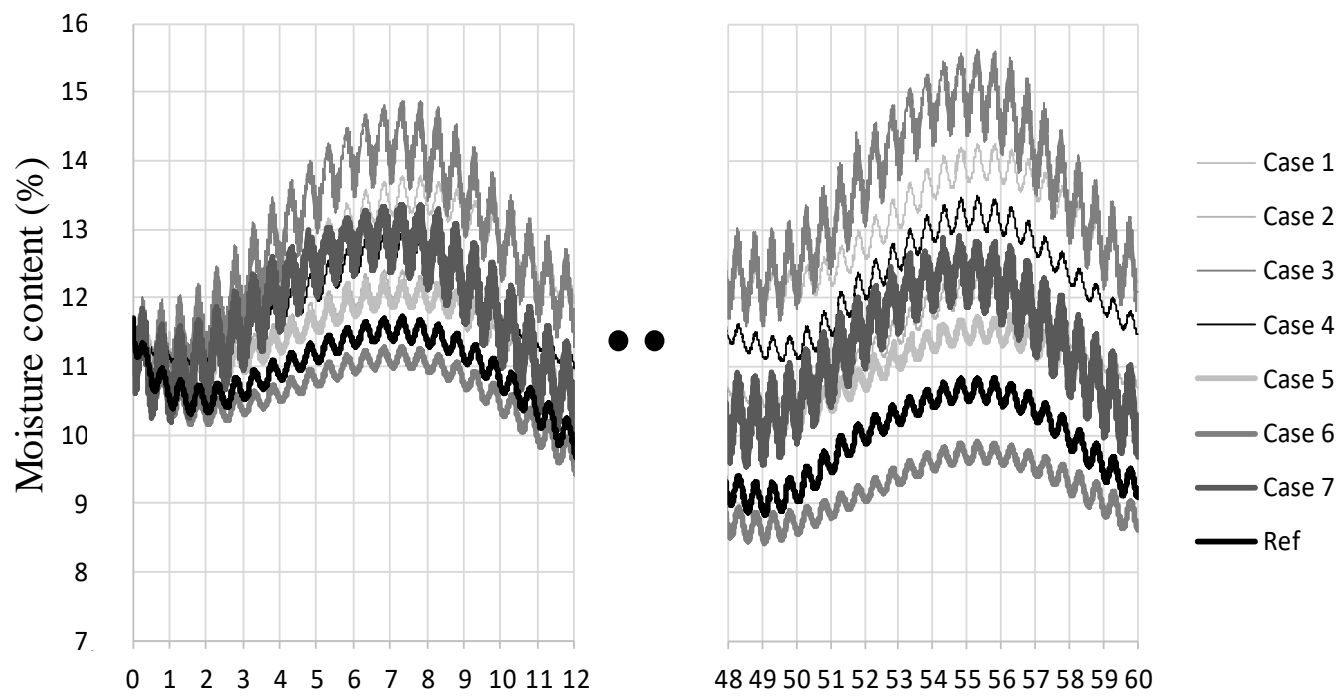

Time (weeks)

Figure 13: Evolution in inner moisture for the first and last years of the 5-year simulation period

- Trend and stabilization level

The final approach applied herein consists of analyzing stabilization trends over the 5-year simulation period.

For each year, the peak values of moisture content $\left(w_{\max } / w_{\min }\right)$ and the average moisture content $\left(w_{\text {mean }}\right)$ for each case have been determined. These quantities were then compared with the initial water content $w_{i}$ of the test piece. Figure 11 depicts for all 8 cases the three criteria for each year. 
It should be noted that cases 2 and 4 reveal a different trend over the first year compared to the four following cases. This result is due to the hypothesis of a homogeneous initial moisture field.

A first analysis on $w_{\text {mean }} / w_{i}$ provides us with the following conclusions on moisture trends:

$\checkmark$ Cases 1, 3 and 4 tend to humidify the specimen.

$\checkmark$ Cases 2, 5, 6, 7 and 8 tend to dry the specimen.

A second analysis of $w_{\max } / w_{i}$ and $w_{\min } / w_{i}$ makes it possible to draw conclusions on the established regimes:

$\checkmark$ Cases 1,2 and 5 reach a steady state as of the $3^{\text {rd }}$ year.

$\checkmark$ Cases 3, 4, 6, 7 and 8 reach a steady state after the $4^{\text {th }}$, if not the $5^{\text {th }}$, year.

These two approaches display the influence of the three phenomena on the long-term equilibrium value, as well as on the speed with which the established regime is attained.

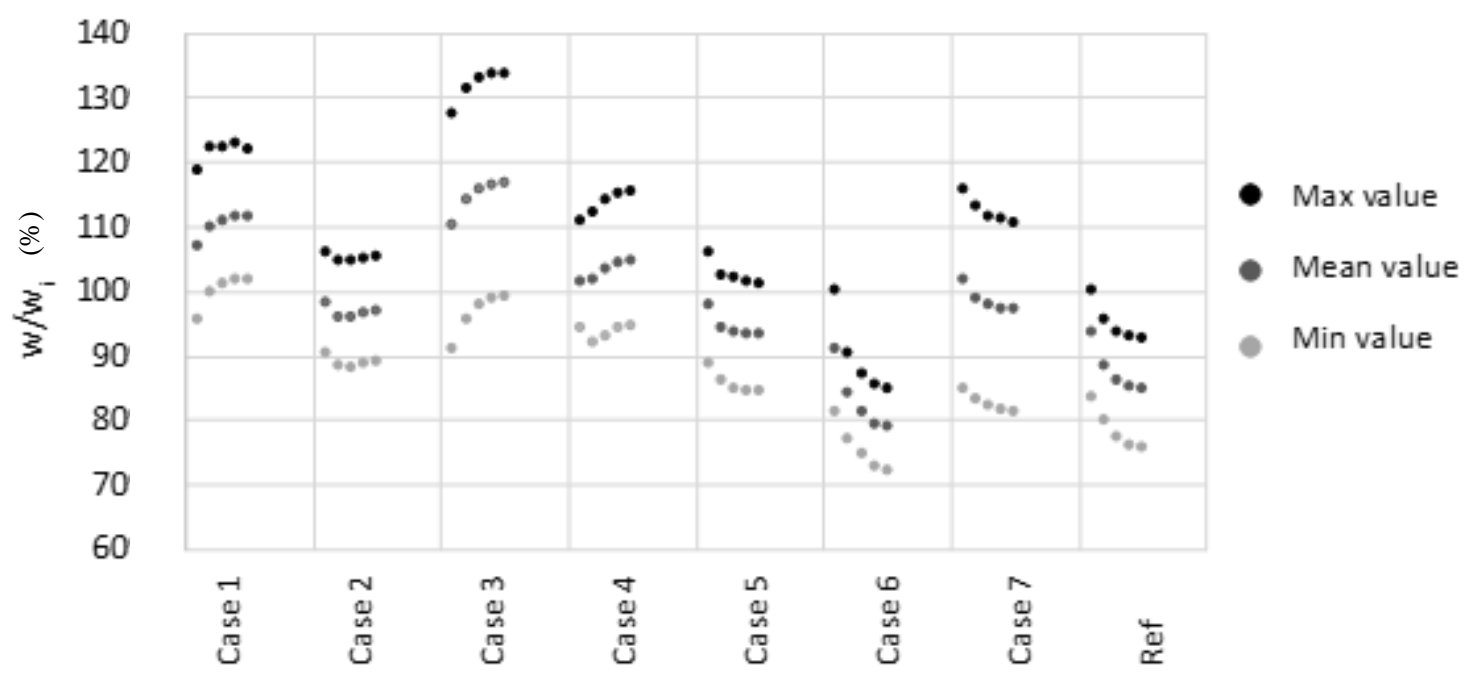

Figure 14: Trend in stabilization levels of the studied cases over 5 years

\section{Conclusion}

This work has focused on mass transfer processes coupled with heat transfer, and particularly on the temperature dependence involved in moisture transfer. In order to model wood element behavior in non-isothermal climates, e.g. timber structures, a strong coupling has been developed. Nevertheless, no phenomenological coupling coefficients could be proposed, as experimental characterization continues to pose a scientific challenge to this day.

Based on a thermodynamic approach, the permeability properties of the material and sorption characteristics have been corrected in accordance with a variable temperature.

The temperature impact on both the average evolution of humidity and the induced water profiles could then be obtained through implementation in a finite element code, namely CASTEM. The mass transfer in a structural element has successfully been modeled without significantly increasing the number of parameters needing to be characterized. 
This approach also removes the ambiguity of using sorption isotherms to manage convective surface water transfers. The proposed model simply provides a thermal correction on the water transport properties between ambient air and the material.

In terms of future outlook, this model could be complemented by considering the liquid water on surfaces, as well as by studying the impact of negative temperatures.

\section{Bibliography}

AFNOR (2010). NF EN 1995-1-1/NA.

Brunauer, S., Emmett, P.H., and Teller, E. (1938). Adsorption of gases in multimolecular layers. J Am Chem Soc 60, 309-319.

Carsten-Rode-Pedersen (1990). Combined heat and moisture transfer in building constructions, Thermal Insulation Laboratory, Technical University of Denmark.

Chen, M., Coasne, B., Guyer, R., Derome, D., Carmeliet, J., Role of hydrogen bonding in hysteresis observed in sorption-induced swelling of soft nanoporous polymers, Nature communications, DOI: 10.1038/s41467-018-05897-9

Choong, E.T. (1963). Movement of moisture through a softwood in the hygroscopic range. For. Prod. J. 13 (11): 489-498

Dent, R.W. (1980). A sorption theory for gas mixtures. Polym. Eng. Sci. 20, 286-289.

Frandsen, H.L. (2007). Selected constitutive models for simulating the hygromechanical response of wood, Dpt of Civil Eng. Aalborg Univ. Denmark.

Hartley, I.D. (1993). Analysis of the wood sorption isotherm using clustering theory. Holzforschung 47, 163-167.

Kulasinski, K. (2015). Physical and mechanical aspects of moisture adsorption in wood biopolymers investigated with atomisitic simulations. ETH Zurich.

Künzel, H.. (1995). Simultaneous heat and moisture transport in building components : Oneand two dimensional calculation using simple parameters (Fraunhofer IRB Verlag).

Li, X., Zhang, B., Li, W., and Li, Y. (2006). Nonisothermal moisture movement in wood. Front. For. China 1, 348-352.

Luikov, A.V. and M., Y.A. (1965). Theory of Energy and Mass Transfer (Pergamon Press).

Merakeb, S. (2006). Couplage hygromécanique dans le processus de diffusion dans le bois, Ph.D. thesis, University of Limoges.

Merakeb, S., Dubois, F., and Petit, C. (2009). Modeling of the sorption hysteresis for wood. Wood Sci. Technol. 43, 575-589.

Nelson, R.M. (1986). Diffusion of bound water in wood-part 3-A model for nonisothermal diffusion. Wood Sci. Technol. 20, 309-328. 
Nelson, R.M. (1991). Heats of transfer and activation energy for bound water diffusion in wood. Wood Sci. Technol. 25, 193-202.

Perré, P., and May, B.K. (2001). A Numerical Drying Model That Accounts for the Coupling Between Transfers and Solid Mechanics. Case of Highly Deformable Products. Dry. Technol. 19, 1629-1643.

Philip, J.R., and Vries, D.A. (1957). Moisture movement in porous materials under temperature gradients. Trans. Am. Geophys. Union 38, 222-232.

Rawat, S.P.S. (1996). Enthalpy-entropy compensation during sorption of water in wood. J. Appl. Polym. Sci. 60, 787-790.

Rosen, H.N. (1976). Exponential dependency of moisture diffusion coefficient. Wood Sci. 8, 174-179.

Siau, J.F. (1971). Flow in wood (Syracuse University Press).

Siau, J.F., and Jin, Z. (1985a). Nonisothermal moisture diffusion experiments analyzed by four alternative equations. Wood Sci. Technol. 19, 151-157.

Siau, J.F., and Jin, Z. (1985b). Nonisothermal moisture diffusion experiments analyzed by four alternative equations. Wood Sci. Technol. 19, 151-157.

Skaar, C. (1988). Wood water relations (Springer-Verlag).

Stamm, A.J. (1959). Bound water diffusion into wood in the fiber direction. For. Prod. J. 9(1), 27-32.

Stamm, A.J. (1964). Wood and cellulose science (Ronald Press Co.).

Varnier M., Sauvat N. , Monterro C., Dubois F., Gril J. (2018), Adaptation of Eurocode 5 standard to French hardwoods - Proposal of new hygroscopic equilibrium charts, 5th INTER meeting Tallinn, Estonia

Zhang C., Coasne B., Guyer R., Derome D., Carmeliet J. (2020), Moisture-induced crossover in the thermodynamic and mechanical response of hydrophilic biopolymer. Cellulose, 27:8999 